\title{
BMJ Open Double-task exercise programmes to strengthen cognitive and vascular health in older adults at risk of cognitive decline: protocol for a randomised clinical trial
}

Rosalinda Sánchez-Arenas, ${ }^{1}$ Svetlana V Doubova (1) , ${ }^{1}$ Mariela Bernabe-Garcia, ${ }^{2}$ Michel A Gregory, ${ }^{3}$ Laura Alejandra Mejía-Alonso, ${ }^{4}$ Oscar Orihuela-Rodríguez, ${ }^{5}$ Carlos Paredes-Manjarrez, ${ }^{6}$ Tania Colín-Martínez, ${ }^{7}$ Irene Mujica-Morales, ${ }^{8}$ Israel Grijalva-Otero, ${ }^{9}$ Lourdes Basurto-Acevedo, ${ }^{10}$ Leticia Manuel-Apolinar, ${ }^{10}$ Juan Cuadros-Moreno, ${ }^{11}$ Arcelia Bernal-Diaz, ${ }^{12}$ Ryosuke Shigematsu ${ }^{13}$

To cite: Sánchez-Arenas $\mathrm{R}$, Doubova SV, BernabeGarcia M, et al. Double-task exercise programmes to strengthen cognitive and vascular health in older adults at risk of cognitive decline: protocol for a randomised clinical trial. BMJ Open 2020;10:e039723. doi:10.1136/ bmjopen-2020-039723

- Prepublication history for this paper is available online. To view these files, please visit the journal online (http://dx.doi org/10.1136/bmjopen-2020039723).

RS-A and RS contributed equally.

Received 27 April 2020 Revised 18 November 2020 Accepted 26 November 2020

Check for updates

(C) Author(s) (or their employer(s)) 2020. Re-use permitted under CC BY-NC. No commercial re-use. See rights and permissions. Published by BMJ.

For numbered affiliations see end of article.

Correspondence to Dr Svetlana V Doubova; svetlana.doubova@gmail.com

\section{ABSTRACT}

Introduction Cognitive and physical declines are frequent causes of disability among older adults (OAs) in Mexico that imposes significant burden on the health system and OAs' families. Programmes to prevent or delay OAs' cognitive and physical decline are scarce.

Methods and analysis A double-blind randomised clinical trial will be conducted. The study will aim to evaluate two 24-week double-task (aerobic and cognitive) square-stepping exercise programmes for $\mathrm{OAs}$ at risk of cognitive decline-one programme with and another without caregiver participation-and to compare these with an aerobic-balance-stretching exercise programme (control group). 300 OAs (100 per group) affiliated with the Mexican Institute of Social Security (IMSS) between 60 and 65 years of age with self-reported cognitive concerns will participate. They will be stratified by education level and randomly allocated to the groups. The intervention will last 24 weeks, and the effect of each programme will be evaluated 12, 24 and 52 weeks after the intervention. Participants' demographic and clinical characteristics will be collected at baseline. The outcomes will include: (1) general cognitive function; (2) specific cognitive functions; (3) dual-task gait; (4) blood pressure; (5) carotid intimamedia thickness; (6) OAs' health-related quality of life; and (7) caregiver burden. The effects of the interventions on each outcome variable will be examined using a repeatedmeasures analysis of variance (ANOVA), with study groups as the between-subjects variable and time as the withinsubject variable.

Ethics and dissemination The study was approved by the IMSS Ethics and Research Committees (registration number: 2018-785-095). All participants will sign a consent form prior to their participation. The study results will be disseminated to the IMSS authorities, healthcare providers and the research community.

Trial registration number ClinicalTrials.gov (NCT04068376).
Strengths and limitations of this study

- The study addresses the important, underinvestigated topic of the effect of double-task training (aerobic and cognitive) on older adults at risk of cognitive decline and on their informal caregivers.

- The study will use a robust double-blind randomised clinical trial design and objective outcomes measured with validated scales.

- The study will include close follow-up of participants through the predesigned monitoring system, mobile text message reminders, and phone calls to participants who fail to attend group sessions or exercise at home.

Due to the budgetary restrictions, it is not feasible to evaluate the long-term effects of the programmes and we will focus only on their mid-term (1 year) effects.

\section{INTRODUCTION}

The Mexican population is ageing. ${ }^{1}$ This demographic change goes hand in hand with the increased deterioration of older adults' physical and cognitive functions. It is projected that the prevalence of dementia will double by $2050 .^{2}$ In older people with cardiovascular risk factors (eg, hypertension, diabetes and obesity), cerebral small vessel disease (CSVD) is often the cause of dementia. CSVD doubles the risk of mild cognitive impairment and Alzheimer's disease $(\mathrm{AD})$ and is present in $80 \%$ of individuals with pathologically confirmed $\mathrm{AD} .^{3}$

In addition, one-third of older adults have gait disorders. ${ }^{45}$ High blood pressure (BP), obesity, diabetes and cardiovascular diseases, and low-physical activity are risk factors for 
gait disorders in this population. ${ }^{6}$ Furthermore, slow gait combined with cognitive complaints is a known motorcognitive risk associated with the occurrence of $\mathrm{AD}$ and vascular dementia. ${ }^{6}$

The cognitive and functional decline of older adults imposes significant burden on the Mexican health system and older adults' families-their main source of supportive care. In Mexico, the informal care provided by daughters has shown potential for reducing the decline in ability to perform instrumental activities of daily living for older adults. ${ }^{7}$ Additionally, the evidence suggests that physical activity reduces the burden on caregivers of older people with dementia. ${ }^{8}$ Therefore, involving caregivers in physical activity programmes for older adults could be beneficial to both groups.

Double-task (DT) training is a multidimensional intervention that combines physical and cognitive tasks. ${ }^{9}$ The 26-week, 3 days per week and $40 \mathrm{~min}$ per day DT training of older adults on a Biodex Gait-Trainer-2 treadmill has shown significant reductions in the time to complete the Trail Making Test (TMT) and improvements in the DigitSymbol Coding Test, phonemic verbal fluency (VF), and immediate and delayed recall, as well as increase in usual speed and step length. ${ }^{9}$ The positive effects of DT training on the cognitive function of older adults suggest that it might be an effective non-pharmacological intervention that can prevent cognitive and functional decline. ${ }^{10}{ }^{11}$ It has been argued that these effects are possible because of DT-training's impact on vascular risks, including mitigating effects on high BP and arterial stiffness-factors associated with several pathological changes in the brain. ${ }^{11}$

Previous research suggests that aerobic exercise can improve cognitive function, including executive function (EF), in healthy older adults and those with nondementia cognitive impairment. ${ }^{12-18} \mathrm{EF}$ is the domain of cognition responsible for planning, attention and multitasking. A decrease in EF is associated with impairments in mobility and other gait activities, ${ }^{19-21}$ including those used during DT training (eg, walking while talking) ${ }^{22}$ Additionally, research has found that aerobic training improves neuronal structural integrity and brain volume. ${ }^{23}$ Although the evidence suggests that the combination of aerobic and cognitive exercises is associated with improved cognition, research supporting the use of DT training (ie, cognitive-motor tasks) to strengthen older adults' cognition is still limited. ${ }^{24-26}$

Square-stepping exercise (SSE) is a group activity that combines aerobic and cognitive exercises. ${ }^{10}$ It is performed on a mat of 250 by $100 \mathrm{~cm}$, divided into squares of $25 \mathrm{~cm}^{2}$. A 6-month $30 \mathrm{~min}$ SSE training plan with one to three sessions a week is recommended. ${ }^{27}$ The instructor uses soft strides ${ }^{27}$ to show movement patterns and older adults have to observe and memorise the patterns and repeat them. ${ }^{27}$ There are 196 step patterns with varying levels of difficulty. The participants should progressively perform more complicated patterns. SSE was designed and tested in Japan to decrease the risk of falls in older adults. SSE research has demonstrated improvements in agility, leg power, locomotion speed, flexibility and balance by strengthening lower-extremity functional fitness and is associated with a significant decrease in falls after tripping. ${ }^{23} 27$ SSE has shown higher effectiveness than strength and balance training. ${ }^{27}$ In addition, due to the DT nature of SSE, it has the potential to strengthen memory and $\mathrm{EFs}^{1027}$; yet, the evidence on the effect of SSE on cognitive functions is scarce.

The growing population of older adults with dementia and gait disorders in Mexico necessitates effective, culturally accepted strategies to prevent cognitive and functional decline. The SSE that combines cognitive and aerobic exercise is a novel, low-cost approach to training for older adults. The SSE programme with the active participation of informal caregivers might be effective to decelerate the cognitive and functional decline of the elderly and ease the caregivers' burden. Currently, Mexican health sector lacks culturally accepted training programmes that address these issues. Therefore, this study will focus on evaluating the cognitive and functional effects of two 24-week DT SSE programmes for older adults at risk of cognitive decline, delivered by health professionals-one programme with and another without caregiver participation-and comparing these with an aerobic-balancestretching exercise programme (control group).

\section{METHODS}

A double-blind randomised clinical trial entitled 'Mind and Movement: Towards the Cognitive Health of Older Adults' will be conducted. The study will include two intervention groups (GR) and one control GR: (1) a DT exercise programme with a squared mat led by a coach (a health professional) for 24 weeks (T1-GR); (2) the same exercise programme led by a coach (a health professional) for 12 weeks and then led by caregivers of older adults for another 12 weeks (T2-GR); and (3) a control group of an aerobic-balance-stretching exercise programme led by a coach for 24 weeks (C-GR).

The study is intended to be a phase 2 clinical trial focuses on exploring the effect of interventions on several outcome variables.

Figure 1 depicts participants flow through the programme.

\section{Eligibility and recruitment}

The participants will be selected from a list of 2600 telephone numbers of community-dwelling older adults who reside in Mexico City and receive healthcare at two primary care clinics of the Mexican Institute of Social Security (IMSS) (figure 1).

We defined the older adults at risk of cognitive decline as those who are: (1) 60-65 years of age; (2) have selfreported cognitive concerns (ie, have answered 'yes' to the question: "Do you feel like your memory or thinking skills have gotten worse recently?"); (3) have one or more vascular risk factor (eg, type 2 diabetes or hypertension); 


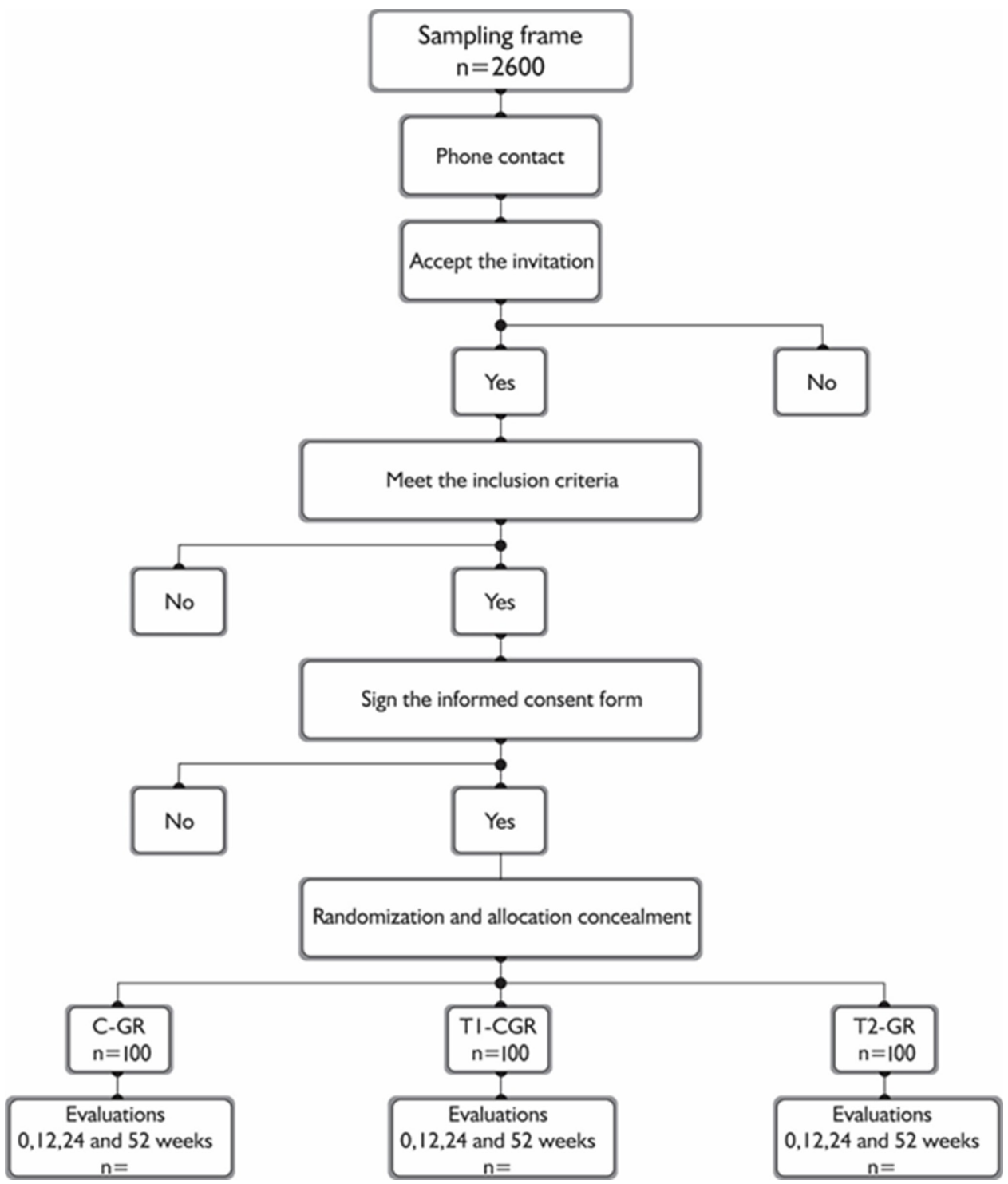

Figure 1 Participants flow through the programme.

(4) do not have a diagnosis of dementia (ie, confirmed by a review of their health records and a Mini Mental State Exam score $>24)^{28}$ and (5) have functional independence in activities of daily living and instrumental activities of daily living. ${ }^{29}$ Another inclusion criterion comprised the availability of informal caregiver who accepts to participate.

We will exclude older adults with: (1) depression (score $>15$ according to the Center for Epidemiological Studies Depression Scale-Revised) ${ }^{30}$; (2) clinically significant neurological or psychiatric disorders (eg, Parkinson's, schizophrenia); (3) a recent severe cardiovascular event (eg, myocardial infarction, stroke); (4) major orthopaedic conditions (eg, severe osteoarthritis); (5) BP that is unsafe for exercise (ie, $>180 / 100 \mathrm{~mm} \mathrm{Hg}$ or $<100 / 60 \mathrm{~mm}$ $\mathrm{Hg})$; (6) severe visual or auditory impairment; or (7) an unwillingness to adhere to the intervention schedules.

Research team will invite all eligible older adults to participate in the study. Initially, older adults will be invited by telephone calls to attend the research unit to receive the study-related information and to undergo a preliminary evaluation to corroborate the study selection criteria. Those who meet the inclusion criteria will ask to sign a consent form prior to participation.

\section{Randomisation and allocation concealment}

To ensure that the groups are balanced with regard to varying levels of education, study participants will be stratified by education (uncomplete/complete elementary, complete secondary or high education) and randomly allocated in blocks of four to one of the intervention groups or the control group. An independent researcher who will not participate in the study will use the Random Allocation Software to generate the allocation sequence. ${ }^{31}$ Each stratum will have its own seed. This researcher will generate uniform random integers, to create the allocation order within each block. She will hold the randomisation file in her computer and will give out the allocations of individual participants one at a time to the three 
Table 1 Sample size

\begin{tabular}{|c|c|c|c|c|c|}
\hline Outcome & Reference & $\delta 0$ & $\delta$ & $S^{2}$ & $\begin{array}{l}\text { Number of participants } \\
\text { per group }\end{array}$ \\
\hline General cognitive function, MoCA & Gill et al, $2016^{53}$ & 0.22 & 1.2 & 0.20 & 49 \\
\hline Trail Making Tests, Part A, seconds & Gill et al, $2016^{53}$ & -0.24 & -0.80 & 0.20 & 25 \\
\hline Trail Making Tests, Part B, seconds & Gill et al, $2016^{53}$ & -0.19 & -0.50 & 0.58 & 6 \\
\hline $\begin{array}{l}\text { Verbal Learning Test, RAVLT- } \\
\text { immediate }\end{array}$ & Gill et al, $2016^{53}$ & 0.56 & 1.00 & 0.44 & 10 \\
\hline Verbal Test, RAVLT-delayed recall & Gill et al, $2016^{53}$ & 0.56 & 1.00 & 0.58 & 17 \\
\hline Verbal fluency, COWA & Gill et., $2016^{53}$ & 0.38 & 1.00 & 0.46 & 6 \\
\hline Walking speed, $\mathrm{cm} / \mathrm{s}$ & Gregory et al, $2017^{9}$ & 0.81 & 1.00 & 0.26 & 83 \\
\hline Walking length, cm & Gregory et al, $2017^{9}$ & 56.10 & 60.00 & 8.20 & 55 \\
\hline Systolic blood pressure, $\mathrm{mm} \mathrm{Hg}$ & Boa Sorte et al, $2018^{10}$ & -2.58 & -3.00 & 0.97 & 66 \\
\hline Diastolic blood pressure, $\mathrm{mm} \mathrm{Hg}$ & Boa Sorte et al, $2018^{10}$ & -1.12 & -2.00 & 1.43 & 32 \\
\hline cIMT, mm & Gregory et al, $2017^{9}$ & -0.63 & -1.00 & 0.12 & 18 \\
\hline clMT, mm & Boa Sorte et al, $2018^{11}$ & -0.001 & -0.013 & 0.01 & 71 \\
\hline $\begin{array}{l}\text { Subjective burden on informal } \\
\text { caregivers }\end{array}$ & Farran et al, $2016^{54}$ & -20.87 & -22.00 & 7.12 & 6 \\
\hline $\begin{array}{l}\text { Patient health-related quality of life, } \\
\text { SF-36 } \\
\text { Physical score }\end{array}$ & Mollinedo et al, $2019^{55}$ & 49.18 & 52.00 & 15.10 & 79 \\
\hline Mental status & & 45.92 & 52.00 & 9.00 & 76 \\
\hline
\end{tabular}

$\delta_{0}=$ treatment effect in the control group; $\delta=$ treatment effect in the intervention group; $S^{2}=$ pooled standard deviation. cIMT, carotid intima-media thickness; COWA, Controlled Oral Word Association; MoCA, Montreal Cognitive Assessment; RAVLT, Rey's Auditory Verbal Learning Test; SF-36, The Short Form Health Survey.

groups. The allocations will be concealed from participants, the study staff involved in enrolment and baseline evaluation.

\section{Patient and public involvement}

Patients or the public will not be involved in the design, or conduct, or reporting, or dissemination plans of our research.

\section{Study hypothesis}

We hypothesise that T1 and T2 DT exercise trainings will show greater improvements in older adults than the control aerobic training with regards to: (1) general cognitive function; (2) specific cognitive functions (EF, processing speed (PS), verbal learning and memory (VLM) and VF); (3) usual walking and dual-task gait; (4) BP; (5) carotid intima-media thickness (cIMT); (6) carotid arterial compliance; (7) older adults' healthrelated quality of life (QoL); and (8) caregiver burden.

\section{Sample size}

The sample size was calculated using the formula suggested by Zong ${ }^{32}$ for continuous outcome variable and clinical superiority design. We considered $\alpha<0.05$, a power of $80 \%$ and the assumptions presented in table 1 . The minimum required sample size, assuming a possible $20 \%$ drop-out rate, is 100 participants per group.

\section{Intervention implementation}

The study will be conducted at IMSS Epidemiology and Health Services Research Unit facilities in Mexico City.

The T1-GR will consist of 60 min training sessions delivered 3 days a week during a 24-week period. Each session will be guided by a health professional with a nursing background previously certified to coach SSE trainings by the Institute of Square-Stepping Exercise in Mie, Japan (Chief Tomohiro Okura and Overseas Director Professor Ryosuke Shigematsu). The coach will show different step patterns and ask participants to observe, memorise and replicate these patterns on the SSE mat. The maximum number of participants per SSE mat will be 10. Participants will be encouraged to help one another by using their hands to point to the patterns that should be replicated. Examples of beginner, intermediate and advanced foot-placement patterns ${ }^{27}$ are depicted in table 2. A group will progress to the next, more challenging step pattern after $80 \%$ of participants can perform the same pattern accurately. For advanced participants, the same pattern can be made more difficult by increasing step speed, avoiding square frames and so on.

In the case of T2-GR, older adults and their caregivers will participate in the same SSE programme led by a coach for 12 weeks; older adults will then be asked to continue SSE at home under the supervision and with the active participation of their caregivers for another 12 weeks. 
Table 2 The patterns for the square-stepping exercise

1) Beginner pattern -focused on walking-like movements and simple steps

\begin{tabular}{|c|c|c|c|c|c|c|c|c|}
\hline \multirow[t]{3}{*}{ Start walk } & 2 & & 4 & & 2 & 4 & & Finish walk \\
\hline & & 3 & & $6^{*}$ & & & 6 & \\
\hline & 1 & & 5 & & 1 & 5 & & \\
\hline
\end{tabular}

Start with the right foot.

2) Intermediate pattern -incorporates forward, lateral and diagonal movements

$\begin{array}{llllllllll}\text { Start walk } & 3 & 5 & 3 & 5 & 3 & 5 & 3 & 5 & \text { Finish walk } \\ & 1 & 4 & 1 & 4 & 1 & 4 & 1 & 4 & 6 \\ & 2 & 6 & 2 & 6^{*} & 2 & 6 & 2 & 6\end{array}$

Start with the left foot.

3) Advanced pattern - a large number of steps per pattern with multiple movement types

$\begin{array}{lllllllllll}\text { Start walk } & 1 & 3 & 7 & 5 & 1 & 3 & 7 & 5 & \text { Finish walk } \\ & 4 & 2 & 6 & 8 & 4 & 2 & 6 & 8 & \end{array}$

Start with the left foot.

${ }^{*}$ Once the pattern is completed, it is repeated until reaching the end of the mat.

They will be asked to practice SSE for $60 \mathrm{~min}$, three times a week and to reach $\mathrm{a} \geq 65 \%$ heart rate increase. In the field of sports, the people who perform the above-mentioned activities are called 'pacers', and they supervise physical activity through active accompaniment of older adults.

\section{Compliance and adverse events monitoring}

A monitoring system will be developed to perform longdistance monitoring of compliance with physical activity. It will include three components: (1) the system that will collect the information from a chipset connected to the SSE mats (eg, time of exercise, velocity); (2) the system that will transmit and store the data on the study computer; (3) the system for supervision and follow-up, which will allow connecting with participants through different electronic devices, such as mobile phones and emails.

The monitoring system will be an important strategy to avoid missing data, dropouts and low-programme adherence.

In addition, we will monitor study adverse events through direct observations of the study participants during the exercise sessions, monitoring system, and 12-week, 24-week and 52-week evaluations.

We will register number, type (eg, dizziness, pain, fatigue, muscle strains, falls or injuries), and severity of adverse events during the exercise sessions and outside the hours of the exercise sessions but during the intervention period. The severity of events will be categorised as follows: mild (do not affect activities of daily living); moderate (have moderate effect on activities of daily living); and severe (requires hospitalisation, or results in persistent or significant disability or results in some life threatening, or other medically important condition). RS-A and AB-D will review all adverse events on a weekly basis. They will report all moderate and severe adverse events to the IMSS Ethics Committee and stop the study if the adverse events data demonstrate any hazard of the intervention.

\section{Motivation strategies}

The monitoring system will be an important strategy to avoid dropouts and low-programme adherence. It will be complemented by motivation phone calls to those participants who fail to attend the group sessions or to perform home-based SES activities.

Moreover, the study will include 10-15 min group discussions to explore health-related topics, such as the benefits of healthy lifestyles (eg, physical activity, nutrition) to maintaining cardiovascular and brain health or to exchange experiences on past events. The discussions will precede exercise training sessions.

\section{Study variables}

The primary outcome variables will be

1. General cognitive function assessed by the Montreal Cognitive Assessment Test on a scale of 0-30 points. Scores are interpreted as follows: $>26$ indicates no dementia, 18-26 mild cognitive impairment, 6-10 moderate dementia and $<6$ severe dementia. ${ }^{33}$

2. Specific domains of cognitive function measured through composite scores for EF/mental flexibility, PS, VLM and VF. EF/mental flexibility will be measured with the TMTs, Part A and Part B (TMT-A and TMT-B). The results for both TMT-A and TMT-B are reported as the number of seconds required to complete a task. ${ }^{34}$ Processing speed (using the Digit Symbol Substitution Test) will be measured as the total correct numbersymbol matches achieved in $90 \mathrm{~s} .{ }^{35}$ VLM will be assessed through Rey's Auditory Verbal Learning Test (RAVLT) that consists of documenting the number of words remembered from a list of 15 words presented in two 
separate moments; this test allows evaluation of the RAVLT-Immediate and RAVLT-Percent Forgetting. ${ }^{36}$ VF (semantic, animal naming and phonemic) will be measured by using the Controlled Oral Word Association Test and assessed through the total number of words identified by category and letter. ${ }^{37}$

\section{The secondary outcomes will include}

1. Usual walking and dual-task gait that will be evaluated through motion capture during the 6 min walk test (6MWT), which requires participants to walk back and forth across a $30 \mathrm{~m}$ area at a comfortable pace for $6 \mathrm{~min}$. The fixed distance used by $6 \mathrm{MWT}$ allows determination of gait speed (ie, $\mathrm{v}=\mathrm{d} / \mathrm{t}$ ); however, this test will also be coupled with infrared stride analysis, which will allow for a more precise evaluation of gait speed, stride length and stride variability under usual and dual-task conditions. These procedures will provide a number of valid and reliable gait outcomes through the synchronisation of mobility data via eight infrared cameras, six force plates and electromyography.

During usual gait assessment, participants will be instructed to perform the 6MWT in isolation (ie, with no cognitive stressor). Additionally, under dual-task conditions, participants will be asked to replicate the $6 \mathrm{MWT}$ while performing simple arithmetic (ie, serial sevens subtraction) or VF (category fluency) tasks. ${ }^{38}$

2. BP will be measured in a standard seated position, using a calibrated digital sphygmomanometer. The measurement will be performed in the brachial artery of the left upper arm in a horizontal position at the level of the heart. At each evaluation (basal and follow-ups), three BP measurements with intervals of 5 min among measurements will be performed, and the average of the three $\mathrm{BP}$ readings will be calculated.

3. cIMT and carotid arterial compliance. Increased cIMT is a marker of cardiovascular risk, and it also predicts a cognitive decline. ${ }^{39-41}$ At the same time, several studies showed the positive effect of physical exercise training programmes on cIMT reduction, ${ }^{942}$ while others failed to confirm this effect. ${ }^{11}$ Therefore, we are interested in evaluating if the study interventions can produce a significant cIMT reduction. cIMT will be measured through an ultrasound of the right common carotid artery. Specifically, a longitudinal B-mode image (Philips HDI 5000 ultrasound, 7-12 MHz linear array transducer) of the cephalic portion of the right common carotid artery will be obtained by a trained ultrasound technician. Recordings will be electrocardiographically gated and obtained for three cardiac cycles. Arterial diameters will be measured from leading edge to leading edge at peak systole and end diastole and subsequently averaged. Afterward, a single measure of resting supine brachial arterial $\mathrm{BP}$ will be obtained using an automated oscillometer following the completion of the ultrasound image acquisition. To minimise the effect of external factors on arterial measures, all ultrasonography assessments will be performed in a quiet, comfortable, temperature-controlled room and participants will be instructed to refrain from the consumption of alcohol and from the participation in moderate-vigorous physical activity for 24 hours prior and from the consumption of caffeine for 12 hours prior to the measurement sessions.

4. Older adults' health-related QoL will be measured by the Short Form Health Survey (SF-12) questionnaire comprised of 12 items. Physical and mental scores will be calculated using an algorithm to convert each item response into standardised values according to specific predetermined weights. ${ }^{43}$ Summary scores for each component range from 0 to 100 and are interpreted as low QoL (close to 0) and high QoL (approaching 100 ).

5. Subjective burden on informal caregivers will be measured using the short form of the Burden Scale for Family Caregivers-a 10-item instrument. Each item is measured on a four-point scale with the values 'strongly disagree' (0), 'disagree' (1), 'agree' (2) and 'strongly agree' (3). A high degree of agreement indicates higher perception of burden by the caregiver. ${ }^{44}$

\section{The study covariates will cover}

Participant demographic and clinical characteristics: age (years from birth); biological sex (male or female); formal educational attainment (years); current employment status (retired, employed, volunteer, unpaid worker, unemployed); marital status (married, widowed, divorced, single, other); and current living situation (living alone, living with a spouse, living with or without children); self-reported comorbidities relevant to this study (eg, vascular risk factors, orthopaedic conditions, etc); and self-reported baseline physical activity defined as (1) ideal ( $\geq 150 \mathrm{~min}$ per week of moderate-intensity activity or $\geq 75$ min per week of vigorous-intensity activity, or an equivalent combination); (2) moderate/intermediate $(\leq 149 \mathrm{~min}$ per week of moderate-intensity activity or $\leq 74 \mathrm{~min}$ per week of vigorous or intense activity, or an equivalent combination); and (3) poor (without any moderate or intense physical activity).$^{45}$

Caregivers will be asked the following: age, biological sex, formal educational attainment, current employment status, marital status, relation to the patient and self-reported baseline physical activity, as previously defined; availability of social support networks; and presence of animal companions at home. Social support will be measured using the Household and Family Support Networks subsection (part 5) of the WHO Study on Global AGEing and Adult Health. ${ }^{46}$

\section{Evaluations}

We will conduct four evaluations during the study: the baseline evaluation and 12-week, 24-week and 52-week evaluations. The study outcome variables will be measured at each evaluation, while the covariates will be collected only at the beginning of the study. We will also measure the participants' adherence to the programmes, defined 
as $80 \%$ or higher compliance with the assigned exercise training regimen. Finally, we will document the reasons for dropouts and poor adherence. Previously trained health professionals with a medical specialty in geriatrics will perform these evaluations.

\section{Data management and confidentiality}

Data entry will be conducted by trained staff. Data quality will be assessed before statistical analysis (eg, range checks for data values).

Only members of the study team will have access to the study information and all information that will be collected from participants will be kept private to ensure confidentiality. The consent forms with participant signatures will be stored in a locked location only accessible by the principal investigator (PI). All electronic data will be stored on the PI laptop and a back-up hard drive which will be password protected. Any handwritten information such as field notes or other related research materials will be stored and secured in a locked cabinet when not in use. Data will be erased and destroyed after 5 years, as per IMSS Ethics and Research Committee guidelines. Only deidentified data will be used for reporting, publication and dissemination of findings.

\section{Statistical analysis}

First, we will perform a descriptive analysis of the older adults' and caregivers' characteristics at each evaluation. We will evaluate the distribution of quantitative variables using the Kolmogorov-Smirnov Normality Test. Variables that have normal distribution will be analysed using means and SD and variables with non-normal distribution will be presented using medians and 25th and 75th percentiles, and categorical variables will be analysed by using frequencies and percentages.

Second, we will examine the effects of the interventions on each outcome variable using a repeated-measures ANOVA, with study groups as the between-subjects variable and time (baseline, week 12, week 24 and week 52) as the within-subject variable. We will perform separate ANOVAs with each dependent variable for each of the following comparisons (1) T1-GR versus C-GR; (2) T2-GR versus C-GR and (3) exploratory analysis T1-GR versus T2-GR. When a 'normality' assumption and homogeneity of variances assumption are violated, a robust repeatedmeasures ANOVA with the Welch procedure will be conducted.

$\mathrm{P}<0.05$ will be interpreted as statistically significant. The analyses will be performed using the software Stata V.14.0 (Stata Corp) and the R (V.3.6.2, 2019-12-12) package.

\section{DISCUSSION}

Low-cost training programmes to improve older adults' physical and cognitive functions that can be implemented both in healthcare facilities and in older adults' homes with the active participation and supervision of informal caregivers might be a key strategy to mitigating the increasing prevalence of disability among older adults. This approach may also lower associated healthcare costs-particularly important in public health institutions in low-income and middle-income countries (LMICs) where healthcare resources are limited.

The IMSS is the largest nationwide social security institution; it provides health benefits to more than 60 million affiliates, among which $12.5 \%$ are $\geq 65$ years of age. ${ }^{47}$ Workers in the formal labour sector secure their IMSS affiliation by making contributions through a progressive payroll tax. In return, affiliates receive full social, economic (pension and disability leave) and health benefits for themselves and their families. Over the last two decades, IMSS has faced increases in healthcare utilisation and expenditures as a result of the ageing demographic of its affiliates and corresponding increases in non-communicable chronic diseases and disabilities. Currently, dementias and falls are the primary causes of years lived with disability among Mexican older adults. ${ }^{48}$ However, IMSS does not have efficient and accessible strategies to prevent or at least delay these deteriorations. In 2010, IMSS launched the Center of Social Health Services for Older Adults (Centro de Atención Social a la Salud de las y los Adultos Mayores (CASSAAM)) to promote the active ageing of affiliated older adults. Evaluations of CASSAAM showed promising results in improving healthrelated QoL and occupational functioning. ${ }^{49}$ However, the services offered under CASSAAM were not expanded due to elevated costs.

The SSE is a low-cost strategy incorporating aerobic and cognitive training that has shown effectiveness for fall prevention through improvements in balance and lower-extremity functional fitness. ${ }^{24}$ In addition to contributing to physical strengthening, SSE requires participants to memorise and repeat up to 196 step patterns, suggesting that SSE could improve older adults' memory. DT training, combining physical and cognitive exercises, might be an effective strategy for reducing the risk of cognitive decline and dementia by reducing small vessel damage-through the targeting of endothelial function-and controlling vascular risk factors. Yet the evidence on the effects of DT training on the vascular risk factors and cognitive function of older adults with mild vascular cognitive impairment and those otherwise at risk of cognitive decline is still limited. ${ }^{26} 50$

In Mexico and in other LMICs, older adults with chronic diseases and disabilities must rely on informal caregivers-usually spouses and adult children-due to a lack of government-funded services and programmes for older adults. ${ }^{51}$ Informal caregivers of older adults frequently present moderate to high levels of physical and emotional burden and report lower QoL and selfrated health than non-caregivers. They are also more likely to have physical multimorbidity. ${ }^{52}$ Therefore, preventive strategies for older adults, such as the SSE training, should involve caregivers to improve their physical and cognitive strength and to decrease their burden. 
The strengths of the proposed study include: (1) the robust randomised controlled trial design considered as a gold standard for evaluating the efficacy of exercise training interventions; (2) close follow-up of participants through the monitoring system, mobile text message reminders and phone calls to prevent low adherence and drop-outs; and (3) outcome variables measured with validated scales.

There are possible limitations to consider as well. Due to budgetary restrictions, it is not feasible to plan the evaluation of long-term effects of the programmes and we will focus only on mid-term (1-year) effects. Finally, funding limitations also impede our ability to use biomarkers and imaging tests.

\section{Ethics and dissemination}

The study was approved by the IMSS Ethics and Research Committee (registration number 2018-785-095). All participants will sign a consent form prior to their participation. The study results will be disseminated to IMSS authorities, healthcare providers and the research community.

\section{Author affiliations}

${ }^{1}$ Epidemiology and Health Services Research Unit CMN Siglo XXI, Mexican Institute of Social Security, Mexico City, Mexico

${ }^{2}$ Medical Research Unit in Nutrition, Pediatrics Hospital, National Medical Center Century XXI, Mexican Institute of Social Security, Mexico City, Mexico

${ }^{3}$ School of Rehabilitation Sciences, Faculty of Health Sciences, McMaster University, Hamilton, Ontario, Canada

${ }^{4}$ Rehabilitation Service, Specialty Hospital, National Medical Center Century XXI, Mexican Institute of Social Security, Mexico City, Mexico

${ }^{5}$ Cardiology Service, Specialty Hospital, National Medical Center Century XXI, Mexican Institute of Social Security, Mexico City, Mexico

${ }^{6}$ Image Service, Specialty Hospital, National Medical Center Century XXI, Mexican Institute of Social Security, Mexico City, Mexico

${ }^{7}$ Continuous Admission Service, Specialty Hospital, National Medical Center Century XXI, Mexican Institute of Social Security, Mexico City, Mexico

${ }^{8}$ Division of Occupational Risk Prevention. Occupational Health Coordination,

Mexican Institute of Social Security, Mexico City, Mexico

${ }^{9}$ Medical Research Unit in Neurological Diseases, National Medical Center Century XXI, Mexican Institute of Social Security, Mexico City, Mexico

${ }^{10}$ Research Unit in Endocrine Diseases, National Medical Center Century XXI,

Mexican Institute of Social Security, Mexico City, Mexico

${ }^{11}$ Coordination of Health Education, Mexican Institute of Social Security, Mexico City, Mexico

${ }^{12}$ Aragón School of Higher Education, National Autonomous University of Mexico,

Mexico City, Mexico

${ }^{13}$ Faculty of Education, Mie University, Tsu, Mie, Japan

Acknowledgements The authors would like to thank Mariajosé Aguilera for editing this paper.

Contributors RS-A: conceptualised the study, elaborated and registered the study protocol at IMSS and wrote the first draft of the manuscript and she is leading the study. SVD participated in the design of the data management and statistical analysis and critically reviewed the manuscript for significant intellectual content. MB-G, MAG, LAM-A, 00-R, CP-M, TC-M, IM-M, IG-0, LB-A, $\mathrm{LM}-\mathrm{A}, \mathrm{JC}-\mathrm{M}, \mathrm{AB}-\mathrm{D}$ and $\mathrm{RS}$ participated in study conceptualisation, preparation of the study proposal that was registered at IMSS. All authors read and approved the final version of the manuscript, have participated sufficiently in the work to take public responsibility for appropriate portions of the content and agreed to be accountable for all aspects of the work in ensuring that questions related to the accuracy or integrity of any part of the work are appropriately investigated and resolved.
Funding The authors have not declared a specific grant for this research from any funding agency in the public, commercial or not-for-profit sectors.

Competing interests None declared.

Patient and public involvement Patients and/or the public were not involved in the design, or conduct, or reporting, or dissemination plans of this research.

Patient consent for publication Not required.

Open access This is an open access article distributed in accordance with the Creative Commons Attribution Non Commercial (CC BY-NC 4.0) license, which permits others to distribute, remix, adapt, build upon this work non-commercially, and license their derivative works on different terms, provided the original work is properly cited, appropriate credit is given, any changes made indicated, and the use is non-commercial. See: http://creativecommons.org/licenses/by-nc/4.0/.

\section{ORCID iD}

Svetlana V Doubova http://orcid.org/0000-0002-0521-7095

\section{REFERENCES}

1 Consejo Nacional de Población. La situación demográfica de México 2017 (text in Spanish). Available: https://www.gob.mx/conapo/ documentos/la-situacion-demografica-de-mexico-2017?idiom=es [Accessed 27 March 2020].

2 García Peña MC, Gutiérrez Robledo M, Medina Campos RH. Introduction. In: Gutiérrez Robledo M, García Peña MC, Medina Campos $\mathrm{RH}$, eds. Envejecimiento Y dependencia. Realidades $Y$ previsión para Los próximos años. México: Academia Nacional de Medicina, 2014: 1-3.

3 Mimenza-Alvarado A. Aguilar-Navarro SG1, Yeverino-Castro S, et al. neuroimaging characteristics of small-vessel disease in older adults with normal cognition, mild cognitive impairment, and Alzheimer disease. Dement Geriatr Cogn Dis Extra 2018;16:199-206.

4 Shigematsu R, Okura T. A novel exercise for improving lowerextremity functional fitness in the elderly. Aging Clin Exp Res 2006;18:242-8

5 Verghese J, LeValley A, Hall CB, et al. Epidemiology of gait disorders in community-residing older adults. J Am Geriatr Soc 2006;54:255-61.

6 Inzitari M, Metti A, Rosano C, et al. Qualitative neurological gait abnormalities, cardiovascular risk factors and functional status in older community-dwellers without neurological diseases: the healthy brain project. Exp Gerontol 2019;124:110652.

7 Trujillo AJ, Mroz TA, Piras C, et al. Caregiving and elderly health in Mexico. Int J Health Serv 2012;42:667-94.

8 Orgeta V, Miranda-Castillo C. Does physical activity reduce burden in carers of people with dementia? A literature review. Int J Geriatr Psychiatry 2014;29:771-83.

9 Gregory MA, Boa Sorte Silva NC, Gill DP, et al. Combined Dual-Task Gait Training and Aerobic Exercise to Improve Cognition, Mobility, and Vascular Health in Community-Dwelling Older Adults at Risk for Future Cognitive Decline1. J Alzheimers Dis 2017:57:747-63.

10 Boa Sorte Silva NC, Gregory MA, Gill DP, et al. The impact of blood pressure dipping status on cognition, mobility, and cardiovascular health in older adults following an exercise program. Gerontol Geriatr Med 2018;4:233372141877033.

11 Gregory MA, Gill DP, Zou G, et al. Group-Based exercise combined with Dual-task training improves gait but not vascular health in active older adults without dementia. Arch Gerontol Geriatr 2016;63:18-27.

12 Colcombe S, Kramer AF. Fitness effects on the cognitive function of older adults: a meta-analytic study. Psychol Sci 2003;14:125-30.

13 Baker LD, Frank LL, Foster-Schubert K, et al. Effects of aerobic exercise on mild cognitive impairment: a controlled trial. Arch Neurol 2010;67:71-9.

14 Lautenschlager NT, Cox KL, Flicker L, et al. Effect of physical activity on cognitive function in older adults at risk for Alzheimer disease: a randomized trial. JAMA 2008;300:1027-37.

15 Middleton L, Kirkland S, Rockwood K. Prevention of CIND by physical activity: different impact on VCl-ND compared with $\mathrm{MCl}$. $J$ Neurol Sci 2008;269:80-4.

16 Kelly ME, Loughrey D, Lawlor BA, et al. The impact of cognitive training and mental stimulation on cognitive and everyday functioning of healthy older adults: a systematic review and meta-analysis. Ageing Res Rev 2014;15:28-43.

17 Willis SL, Tennstedt SL, Marsiske M, et al. Long-Term effects of cognitive training on everyday functional outcomes in older adults. JAMA 2006;296:2805-14. 
18 Klusmann V, Evers A, Schwarzer R, et al. Complex mental and physical activity in older women and cognitive performance: a 6-month randomized controlled trial. J Gerontol A Biol Sci Med Sci 2010;65:680-8.

19 Holtzer R, Verghese J, Xue X, et al. Cognitive processes related to gait velocity: results from the Einstein aging study. Neuropsychology 2006;20:215-23.

20 Springer S, Giladi N, Peretz C, et al. Dual-tasking effects on gait variability: the role of aging, falls, and executive function. Mov Disord 2006;21:950-7.

21 Verghese J, Robbins M, Holtzer R, et al. Gait dysfunction in mild cognitive impairment syndromes. J Am Geriatr Soc 2008;56:1244-51.

22 Montero-Odasso M, Muir SW, Speechley M. Dual-Task complexity affects gait in people with mild cognitive impairment: the interplay between gait variability, dual tasking, and risk of falls. Arch Phys Med Rehabil 2012;93:293-9.

23 Cheng S-T. Cognitive reserve and the prevention of dementia: the role of physical and cognitive activities. Curr Psychiatry Rep 2016;18:85

24 Shigematsu R, Okura T, Nakagaichi M, et al. Square-stepping exercise and fall risk factors in older adults: a single-blind, randomized controlled trial. J Gerontol A Biol Sci Med Sci 2008;63:76-82.

25 Daviglus ML, Plassman BL, Pirzada A, et al. Risk factors and preventive interventions for Alzheimer disease: state of the science. Arch Neurol 2011;68:1185-90.

26 Gates N, Fiatarone Singh MA, Sachdev PS, et al. The effect of exercise training on cognitive function in older adults with mild cognitive impairment: a meta-analysis of randomized controlled trials. Am J Geriatr Psychiatry 2013;21:1086-97.

27 Shigematsu R, Okura T. A novel exercise for improving lowerextremity functional fitness in the elderly. Aging Clin Exp Res 2006;18:242-8

28 Folstein MF, Folstein SE, McHugh PR. "Mini-mental state". A practical method for grading the cognitive state of patients for the clinician. J Psychiatr Res 1975;12:189-98.

29 Cabañero-Martínez MJ, Cabrero-García J, Richart-Martínez M, et al. [Structured review of activities of daily living measures in older people]. Rev Esp Geriatr Gerontol 2008;43:271-83.

30 Kohout FJ, Berkman LF, Evans DA, et al. Two shorter forms of the CES-D (center for epidemiological studies depression) depression symptoms index. J Aging Health 1993;5:179-93.

31 Saghaei M. Random allocation software for parallel group randomized trials. BMC Med Res Methodol 2004;4:26.

32 Zhong B. How to calculate sample size in randomized controlled trial? J Thorac Dis 2009;1:51-4.

33 Aguilar-Navarro SG, Mimenza-Alvarado AJ, Palacios-García AA, et al. Validity and reliability of the Spanish version of the Montreal cognitive assessment (MoCA) for the detection of cognitive impairment in Mexico. Rev Colomb Psiquiatr 2018;47:237-43.

34 Gaudino EA, Geisler MW, Squires NK. Construct validity in the TRAIL making test: what makes Part B harder? J Clin Exp Neuropsychol 1995;17:529-35

35 Rosano C, Perera S, Inzitari M, et al. Digit symbol substitution test and future clinical and subclinical disorders of cognition, mobility and mood in older adults. Age Ageing 2016;45:687-94.

36 Moradi E, Hallikainen I, Hänninen T. Alzheimer's Disease Neuroimaging Initiative. Rey's Auditory Verbal Learning Test scores can be predicted from whole brain MRI in Alzheimer's disease. Neuroimage Clin 2016;18:415-27.

37 Malek-Ahmadi M, Small BJ, Raj A. The diagnostic value of controlled oral word association test-FAS and category fluency in singledomain amnestic mild cognitive impairment. Dement Geriatr Cogn Disord 2011;32:235-40.
38 Gochicoa-Rangel L, Mora-Romero U, Guerrero-Zúñiga S. Prueba de caminata de 6 minutos: recomendaciones $Y$ procedimientos. Neumol Cir Tórax 2015;74:127-36.

39 Sander K, Bickel H, Förstl H, et al. Carotid- intima media thickness is independently associated with cognitive decline. The invade study. Int J Geriatr Psychiatry 2010;25:389-94.

40 Komulainen P, Kivipelto M, Lakka TA, et al. Carotid intima-media thickness and cognitive function in elderly women: a populationbased study. Neuroepidemiology 2007;28:207-13.

41 Moon JH, Lim S, Han JW, et al. Carotid intima-media thickness is associated with the progression of cognitive impairment in older adults. Stroke 2015;46:1024-30.

42 Byrkjeland R, Stensæth K-H, Anderssen S, et al. Effects of exercise training on carotid intima-media thickness in patients with type 2 diabetes and coronary artery disease. Influence of carotid plaques. Cardiovasc Diabetol 2016;15:13.

43 Ware JE, Kosinski M, Keller SD. SF12: how to score SF12 physical and mental health summary scales. 2nd ed. Boston, MA: The Health Institute. New England Medical Center, 1995: 11-27.

44 Graessel E, Berth H, Lichte T, et al. Subjective caregiver burden: validity of the 10-item short version of the burden scale for family caregivers BSFC-s. BMC Geriatr 2014;14:23.

45 Dhamoon MS, Dong C, Elkind MSV, et al. Ideal cardiovascular health predicts functional status independently of vascular events: the Northern Manhattan study. J Am Heart Assoc 2015;4:12.

46 World Health Organization. Study of global ageing and adult health (SAGE). survey manual. Available: https://www.who.int/healthinfo/ survey/SAGESurveyManualFinal.pdf [Accessed 27 March 2020].

47 Instituto Mexicano del Seguro Social. Informe al Ejecutivo federal Y al Congreso de la Unión Sobre La situación financiera Y Los riesgos del Instituto Mexicano del Seguro social 2017-2018. Ciudad de México DF: Instituto Mexicano del Seguro Social, 2018. http:// www.imss.gob.mx/sites/all/statics/pdf/informes/20172018/21InformeCompleto.pdf

48 Parra-Rodríguez L, González-Meljem JM, Gómez-Dantés H, et al. The burden of disease in Mexican older adults: premature mortality challenging a Limited-Resource health system. J Aging Health 2020;32:543-53.

49 Pérez-Cuevas R, Doubova SV, Bazaldúa-Merino LA, et al. A social health services model to promote active ageing in Mexico: design and evaluation of a pilot programme. Ageing Soc 2015;35:1457-80.

50 Dao E, Hsiung GR, Liu-Ambrose T. The role of exercise in mitigating subcortical ischemic vascular cognitive impairment. J Neurochem 2018;144:582-94.

51 Lambert SD, Bowe SJ, Livingston PM, et al. Impact of informal caregiving on older adults' physical and mental health in low-income and middle-income countries: a cross-sectional, secondary analysis based on the WHO's Study on global AGEing and adult health (SAGE). BMJ Open 2017;7:e017236.

52 Jacob L, Oh H, Shin Jl. Informal caregiving, chronic physical conditions, and physical multimorbidity in 48 low- and middleincome countries. J Gerontol A Biol Sci Med Sci 2020.

53 Gill DP, Gregory MA, Zou G, et al. The healthy mind, healthy mobility trial: a novel exercise program for older adults. Med Sci Sports Exerc 2016;48:297-306.

54 Farran CJ, Paun O, Cothran F, et al. Impact of an individualized physical activity intervention on improving mental health outcomes in family caregivers of persons with dementia: a randomized controlled trial. AIMS Med Sci 2016;3:15-31.

55 Mollinedo Cardalda I, López A, Cancela Carral JM. The effects of different types of physical exercise on physical and cognitive function in frail institutionalized older adults with mild to moderate cognitive impairment. A randomized controlled trial. Arch Gerontol Geriatr 2019;83:223-30. 